\title{
Excessive Erythrocytosis and Cardiovascular Risk in Andean Highlanders
}

\author{
Noemí Corante, ${ }^{1}$ Cecilia Anza-Ramírez, ${ }^{1}$ Rómulo Figueroa-Mujíca, ${ }^{1}$ José Luis Macarlupú, ${ }^{1}$ \\ Gustavo Vizcardo-Galindo, ${ }^{1}$ Grzegorz Bilo, ${ }^{2,3}$ Gianfranco Parati, ${ }^{2,3}$ Jorge L. Gamboa, ${ }^{4}$ \\ Fabiola León-Velarde, ${ }^{1}$ and Francisco C. Villafuerte ${ }^{1}$
}

\begin{abstract}
Corante, Noemí, Cecilia Anza-Ramírez, Rómulo Figueroa-Mujíca, José Luis Macarlupú, Gustavo Vizcardo-Galindo, Grzegorz Bilo, Gianfranco Parati, Jorge L. Gamboa, Fabiola León-Velarde, and Francisco C. Villafuerte. Excessive erythrocytosis and cardiovascular risk in Andean highlanders. High Alt Med Biol. 19:221-231, 2018. - Cardiovascular diseases are the main cause of death worldwide. Life under high-altitude (HA) hypoxic conditions is believed to provide highlanders with a natural protection against cardiovascular and metabolic diseases compared with sea-level inhabitants. However, some HA dwellers become intolerant to chronic hypoxia and develop a progressive incapacitating syndrome known as chronic mountain sickness (CMS), characterized by excessive erythrocytosis (EE; $\mathrm{Hb} \geq 21 \mathrm{~g} / \mathrm{dL}$ in men, $\mathrm{Hb} \geq 19 \mathrm{~g} / \mathrm{dL}$ in women). Evidence from HA studies suggests that, in addition to CMS typical signs and symptoms, these highlanders may also suffer from metabolic and cardiovascular disorders. Thus, we hypothesize that this syndrome is also associated to the loss of the cardiometabolic protection observed in healthy highlanders $(\mathrm{HH})$, and therefore to a higher cardiovascular risk (CVR). The aim of the present work was to evaluate the association between EE and CVR calculated using the Framingham General CVR Score and between EE and CVR factors in male highlanders. This cross-sectional study included 342 males from Cerro de Pasco, Peru at $4340 \mathrm{~m}(\mathrm{HH}=209, \mathrm{CMS}=133)$. Associations were assessed by multiple logistic regressions adjusted for potential confounders (BMI, pulse oxygen saturation and age). The adjusted models show that the odds of high CVR $(>20 \%)$ in highlanders with EE was 3.63 times the odds in $\mathrm{HH}$ (CI 95\%:1.22-10.78; $p=0.020)$, and that $\mathrm{EE}$ is associated to hypertension, elevated fasting serum glucose, insulin resistance, and elevated fasting serum triglycerides. Our results suggest that individuals who suffer from EE are at increased risk of developing cardiovascular events compared with their healthy counterparts.
\end{abstract}

Keywords: andean highlanders; cardiovascular risk; chronic mountain sickness; excessive erythrocytosis

\section{Introduction}

C ARDIOVASCULAR DISEASES are the main cause of death worldwide (WHO, 2016), leading to the need for population-specific evaluation of cardiovascular risk (CVR) factors around the globe. Studies at high altitude (HA) have suggested that life in chronic hypoxia confers highlanders with a natural protection against the development of cardiovascular conditions such as hypertension (Hurtado, 1960; Marticorena et al., 1969; Negi et al., 2012), myocardial infarction, and coronary ischemic disease (Mortimer et al., 1977; Faeh et al., 2009); as well as against CVR factors such as diabetes (Picon Reategui, 1963; Woolcott et al., 2015) and dyslipidemia (Bellido et al., 1993; Baracco et al., 2006). However, a significant part of the HA population show reduced capacity to tolerate life in chronic hypoxia and develop excessive erythrocytosis (EE) and chronic mountain sickness (CMS). For this reason, CMS is considered to reflect nonadaptation to the HA environment.

CMS is a progressive incapacitating syndrome characterized by $\mathrm{EE}$ ( $\mathrm{Hb}$ concentration $\geq 21 \mathrm{~g} / \mathrm{dL}$ in men and $\geq 19 \mathrm{~g} / \mathrm{dL}$ in women), severe hypoxemia, and by signs and symptoms such as headache, dizziness, breathlessness and/or palpitations, sleep disturbances, physical and mental fatigue, distended veins,

\footnotetext{
${ }^{1}$ Laboratorio de Fisiología Comparada, Departamento de Ciencias Biológicas y Fisiológicas, Facultad de Ciencias y Filosofía, Universidad Peruana Cayetano Heredia. Lima, Perú.

${ }^{2}$ Department of Medicine and Surgery, University of Milano-Bicocca, Milano, Italy.

${ }^{3}$ Department of Cardiovascular, Neural and Metabolic Sciences, IRCCS Istituto Auxologico Italiano, Milano, Italy.

${ }^{4}$ Division of Clinical Pharmacology, Vanderbilt University Medical Center, Nashville, Tennessee.

(C) Noemí Corante et al., 2018; Published by Mary Ann Liebert, Inc. This Open Access article is distributed under the terms of the Creative Commons License (http://creativecommons.org/licenses/by/4.0), which permits unrestricted use, distribution, and reproduction in any medium, provided the original work is properly cited.
} 
and localized cyanosis (León-Velarde et al., 2005). Globally, $5 \%-10 \%$ of the $\sim 140$ million people living above $2500 \mathrm{~m}$ develop EE and CMS (León-Velarde et al., 2005). In Peru, where about a third of the population lives at HA (INEI, 2007), epidemiological studies in the Andes above $4000 \mathrm{~m}$ report CMS prevalence between $15 \%$ and $20 \%$ in the adult male population. CMS prevalence increases with age, reaching $30 \%$ by the sixth decade of life (Monge-C et al., 1992). This syndrome not only represents a major health problem for highlanders but also hinders their occupational life.

Evidence suggests that in addition to the CMS symptomatology, these individuals may also suffer from metabolic and cardiovascular disorders that could contribute to a greater CVR and worsen their health status and living conditions (León-Velarde and Arregui, 1994; Jefferson et al., 2002; Okumiya et al., 2010, 2011, 2016; Gonzales and Tapia, 2013; De Ferrari et al., 2014). Studies in HA populations of Asia and the Andes have shown an association between elevated $\mathrm{Hb}$ concentration $(>18 \mathrm{~g} / \mathrm{dL})$ and glucose intolerance $(\mathrm{Oku}-$ miya et al., 2010, 2011, 2016), indicating a poor glycemic control in individuals presenting abnormally high $\mathrm{Hb}$ values for the altitude of residence (Okumiya et al., 2010, 2011, 2016). Also, a positive correlation was observed between increasing $\mathrm{Hb}$ concentration and conventional systolic blood pressure (SBP) and diastolic blood pressure (DBP) values in Cerro de Pasco, Perú at $4340 \mathrm{~m}$ (Gonzales and Tapia, 2013). Moreover, in studies at the same location, highlanders with EE showed a higher prevalence of hypertension, compared with their healthy counterparts (León-Velarde and Arregui, 1994; Jefferson et al., 2002). Although lipid metabolism has not been thoroughly investigated in individuals with EE, recent studies report an association between high $\mathrm{Hb}$ concentration and triglyceride levels (Gonzales and Tapia, 2013), and a higher prevalence of metabolic syndrome in the CMS population compared with healthy HA natives (De Ferrari et al., 2014).

Elevated hematocrit (Hct) also contributes to increased blood viscosity and thus, to higher risk of occlusive vascular disease and coronary heart disease (Danesh et al., 2000). Furthermore, elevated Hct might play a role in the development of metabolic disorders in individuals with EE through its effect on blood viscosity (Hanley et al., 2009). These findings suggest a negative effect of elevated red blood cell count on cardiometabolic parameters and CVR. However, to date, no study has specifically evaluated the risk of cardiovascular events in individuals with EE. We hypothesize that EE is associated to an increased CVR compared with healthy HA natives.

Underdiagnosis of high CVR and of the associated cardiometabolic alterations is common in developing countries (Gakidou et al., 2011) and is related to a lack of appropriate public health policies (WHO, 2014). Given that cardiovascular diseases are a major cause for mortality, especially in developing countries such as Peru (WHO, 2014, 2016), and CMS is a highly prevalent syndrome in Latin American highlanders, it is crucial that the cardiometabolic status of CMS patients is fully understood so that accurate and efficient strategies for the prevention and treatment of cardiometabolic disorders and increased CVR can be developed for this population. The aim of the present study was to assess the association between EE and high CVR, as well as between $\mathrm{EE}$ and individual CVR factors. In addition, we evaluated the association between EE and $24 \mathrm{~h}$ blood pressure measured by Ambulatory Blood Pressure Monitoring (ABPM).

\section{Methods}

\section{Study design and population}

This analytic cross-sectional study enrolled 209 healthy highlanders $(\mathrm{HH})$ and 133 individuals with EE, all native and permanent residents of Cerro de Pasco, Peru, at $4340 \mathrm{~m}$. Permanent residence at $\mathrm{HA}$ was defined as life-long permanence in the city with total time spent at a lower altitude shorter than 1 year. All participants were males between 18 and 66 years old. A nonprobabilistic convenience sampling method was used for recruitment of all participants. To this end, a Hct and blood pressure control campaign for the general Cerro de Pasco population was offered and advertised through radio broadcasting and through print advertising distributed throughout the city. Exclusion criteria were previous history of cardiovascular, respiratory or renal diseases, blood transfusions or phlebotomies in the previous 6 months, journeys to lower altitude for more than 7 days during the previous 6 months, and abnormal cardiac or pulmonary function evaluated through electrocardiogram and spirometry, respectively. Subjects with Hct $\geq 63 \%$ (Hb concentration $\geq 21 \mathrm{~g} / \mathrm{dL}$ ) were selected as participants with EE (León-Velarde et al., 2005), while subjects with Hct $\leq 58.5 \%$ were selected as healthy HA natives. The study was approved by the Ethics Committee of Universidad Peruana Cayetano Heredia, and all participants signed an informed consent. This study was developed in collaboration with the HIGHCARE-ANDES study.

\section{Study procedures}

All participants underwent thorough clinical examination. Office blood pressure was obtained using a validated oscillometric device (UA-767 Plus; A\&D Medical, Japan). Diagnosis of hypertension using office blood pressure used thresholds of SBP $\geq 140 \mathrm{mmHg}$ or DBP $\geq 90 \mathrm{mmHg}$. Average of three measurements performed in seated position after 5 minute rest was considered. Oxygen saturation $\left(\mathrm{SpO}_{2}\right)$ was measured by pulse oximetry (Nellcor N-560, Nellcor Puritan Bennett Inc., USA). Low arterial oxygen saturation was defined as $\mathrm{SpO}_{2}$ $<83 \%$ (Monge-C et al., 1992). Hct was measured because of its in-field practicality and was determined in duplicate by microcentrifugation using a small blood sample obtained from a puncture on the fingertip. Blood samples were collected after $\sim 8-10$ hour fasting from the antecubital vein, from which serum was obtained for the measurement of glucose, insulin, cholesterol and triglycerides concentrations, and iron profiling. Diabetes and impaired fasting glucose were determined as serum morning glucose $>126 \mathrm{mg} / \mathrm{dL}$ and $>100 \mathrm{mg} / \mathrm{dL}$, respectively. Insulin resistance was determined using the Homeostasis Model Assessment 2 (HOMA2) as HOMA2-IR $>1.8$. Hypercholesterolemia and hypertriglyceridemia were defined as serum cholesterol $>200 \mathrm{mg} / \mathrm{dL}$ and triglycerides $>150 \mathrm{mg} / \mathrm{dL}$, respectively. In addition, oral glucose tolerance tests were performed in a subset of participants $(\mathrm{HH}=27$, $\mathrm{EE}=27$ ), using a standard method (Aparicio et al., 1974), and the area under the curve was calculated using the trapezoidal rule (Le Floch et al., 1990).

\section{CVR assessment}

The risk of cardiovascular events (stroke, transient cerebral ischemic attacks, myocardial infarction and angina episodes, hospitalization for cardiac decompensation, peripheral artery disease, and cardiovascular mortality) in the following 
10 years was calculated for all participants using the Framingham General Cardiovascular Risk Score, which has been validated in Latin America (D'Agostino et al., 2001, 2008). Parameters used for the calculation of the CVR score are age, smoking status, diabetic status, conventional SBP values, total serum cholesterol, and serum high-density lipoprotein (HDL) cholesterol concentrations. High CVR was determined as CVR > 20\% (D'Agostino et al., 2008).

\section{Questionnaires}

All participants answered a general health and a CMS score questionnaire (León-Velarde et al., 2005). The CMS score measures the severity of the syndrome and is defined based on the following signs and symptoms: EE, shortness of breath or palpitations, sleep disturbances, paresthesias, headache, cyanosis, dilated veins, and tinnitus (León-Velarde et al., 2005). For participants with EE, CMS score was categorized as preclinical (EE only), mild (6-10), or moderate to severe (11-21). Also, a subset of participants completed the international physical activity questionnaire, IPAQ (Craig et al., 2003), from which time in sedentary activities was obtained based on quantity and quality of physical exercise. A trained professional applied all questionnaires.

\section{Ambulatory blood pressure monitoring}

Twenty-four hour ABPM was performed using a validated oscillometric device (TM2430; A\&D Medical, Japan) applied on the nondominant arm. The measurements took place every 15 minutes during daytime $(6.00-23.00 \mathrm{~h})$ and every $20 \mathrm{~min}-$ utes during night-time $(23.00-6.00 \mathrm{~h})$. Patients were asked to stay still during the recordings and keep a standardized activity journal. Valid ABPM recordings were those with at least $70 \%$ of expected readings available and which did not contain two or more consecutive hours without valid readings. Variables obtained from the recordings were systolic, diastolic, and mean daytime (awake), night-time (sleep), and $24 \mathrm{~h}$ blood pressure. ABPM thresholds for hypertension were $135 / 85 \mathrm{mmHg}$ for daytime, $120 / 70 \mathrm{mmHg}$ for night-time and $130 / 80 \mathrm{mmHg}$ for 24h (O'Brien et al., 2013). Also, BP variability, evaluated through standard deviation (SD) of average $24 \mathrm{~h}$, daytime and night-time ABPM values, was analyzed (Mancia et al., 1993).

\section{Statistical analysis}

STATA14 software was used for all statistical analysis. Primary end point was the association between the presence of EE and high CVR; secondary end points were the association between $\mathrm{EE}$ and CVR factors individually considered, and differences in ambulatory blood pressure parameters. For comparison of means between groups (HH vs. EE), the normality distribution and homogeneity of variance of all continuous variables were assessed to determine the use of parametric (Student's $t$-test) or nonparametric (Wilcoxon signed-rank) tests. The association between EE and CVR and between EE and cardiometabolic parameters independently was evaluated through multivariate logistic regressions, which included known confounders (age, BMI, and $\mathrm{SpO}_{2}$ ). Physical activity was not included as a potential confounder since there was no association between this parameter and either of the study variables. In addition, bivariate associations were evaluated using logistic regressions. A p-value below 0.05 was considered as the minimum level of statistical significance. In addition, a sensitivity analysis was conducted using propensity score matching to determine de effect of EE on CVR. Nearest neighbor with replacement method was used to match subjects with $\mathrm{EE}$ and $\mathrm{HH}$ whose propensity scores are closer. The method was used to balance the $\mathrm{EE}$ and $\mathrm{HH}$ groups so that direct comparison would be possible for evaluation of the average treatment effect (ATE) of EE on CVR. The variables included in the calculation of the propensity scores were age, BMI, and $\mathrm{SpO}_{2}$.

\section{Results}

\section{General characteristics}

As expected, Hct and CMS scores were higher in participants with EE compared to $\mathrm{HH}$, while $\mathrm{SpO}_{2}$ showed lower values. Also, subjects with EE showed higher BMI, heart rate, and age. Regression analysis showed no association between EE and heart rate in a model adjusted for known confounding factors (age, $\mathrm{BMI}$, and $\mathrm{SpO}_{2}$ ); while there was a significant inverse association between heart rate and $\mathrm{SpO}_{2}$. Iron profile parameters showed normal values in EE subjects, except for lower serum ferritin. Time spent in sedentary activities or smoking status was not statistically different between $\mathrm{HH}$ and participants with EE (Table 1).

\section{Cardiovascular risk}

Multivariate logistic regression showed that the odds of CVR $>20 \%$ in participants with EE 3.6 times the odds in $\mathrm{HH}$, in a model adjusted for overweight and obesity, $\mathrm{SpO}_{2}$, and age (Table 2). In addition, a bivariate association was observed between CMS score and CVR. The results from the sensitivity analysis show a statistically significant ATE of EE and CVR (Table 3), supporting the results from the multivariate regression.

\section{Metabolic parameters}

Morning fasting serum glucose concentration was significantly higher in the EE group compared with HH (95.3 vs.

Table 1. General Characteristics of Healthy Highlanders AND SUBJECTS WITH EXCESSIVE ERYTHROCYTOSIS

\begin{tabular}{|c|c|c|c|c|}
\hline & \multicolumn{2}{|c|}{$H H(\mathrm{n}=209)$} & \multicolumn{2}{|c|}{$E E(\mathrm{n}=133)$} \\
\hline & Mean & SEM & Mean & SEM \\
\hline Age, yrs & 40.7 & 0.9 & $44.6 * *$ & 1.0 \\
\hline BMI, $\mathrm{kg} / \mathrm{m}^{2}$ & 24.9 & 0.2 & $26.4 * * *$ & 0.3 \\
\hline $\begin{array}{l}\text { Time in sedentary } \\
\text { activities, hrs }\end{array}$ & 4.0 & 0.4 & 5.1 & 0.5 \\
\hline CMS score & 1.8 & 0.1 & $7.5 * * *$ & 0.3 \\
\hline Hematocrit, $\%$ & 53.3 & 0.2 & $67.4 * * *$ & 0.4 \\
\hline Hemoglobin, g/dL & 17.8 & 0.1 & $22.5^{* * *}$ & 0.1 \\
\hline $\mathrm{SpO}_{2}, \%$ & 88.2 & 0.2 & $84 * * *$ & 0.3 \\
\hline Heart rate, beats/min & 67.5 & 0.7 & $72.1 * *$ & 1.0 \\
\hline Serum iron, $\mu \mathrm{g} / \mathrm{dL}$ & 111.3 & 3.5 & 105.6 & 5.5 \\
\hline Serum ferritin, ng/dL & 168.1 & 16.0 & $125.4 * *$ & 13.7 \\
\hline Serum transferrin, $\mathrm{mg} / \mathrm{dL}$ & 303.1 & 5.4 & 308.6 & 7.1 \\
\hline
\end{tabular}

$* * p<0.01$ versus $\mathrm{HH}$.

$* * * p<0.001$ versus $\mathrm{HH}$.

BMI, body mass index; CMS, chronic mountain sickness; EE, excessive erythrocytosis; $\mathrm{HH}$, healthy highlanders; $\mathrm{SpO}_{2}$, pulse oxygen saturation. 
Table 2. Association Between Excessive Erythrocytosis and Cardiovascular Risk

\begin{tabular}{|c|c|c|c|c|c|c|}
\hline \multirow[b]{2}{*}{ Variables } & \multicolumn{3}{|c|}{ Bivariate analysis } & \multicolumn{3}{|c|}{ Adjusted model* } \\
\hline & $O R$ & CI $95 \%$ & $\mathrm{p}$ value & $O R$ & CI $95 \%$ & $\mathrm{p}$ value \\
\hline Overweight and obesity & & & 0.132 & & & 0.803 \\
\hline No & Reference & & & Reference & & \\
\hline Yes & 1.9 & $0.8-4.2$ & & 1.1 & $0.41-3.1$ & \\
\hline $\mathrm{SpO}_{2}(\%)$ & & & 0.333 & & & 0.729 \\
\hline$\geq 83 \%$ & Reference & & & Reference & & \\
\hline$<83 \%$ & 1.6 & $0.6-4.2$ & & 0.4 & $0.1-1.5$ & \\
\hline Age & 1.26 & $1.16-1.37$ & 0.000 & 1.28 & $1.16-1.41$ & 0.000 \\
\hline CMS score & & & 0.0273 & & & \\
\hline Preclinical & Reference & & & & & \\
\hline Mild & 2.7 & $1.2-6.5$ & & & & \\
\hline Moderate and severe & 3.5 & $1.0-11.9$ & & & & \\
\hline $\mathrm{EE}$ & & & 0.014 & & & 0.020 \\
\hline No & Reference & & & Reference & & \\
\hline Yes & 2.7 & $1.2-6.0$ & & 3.6 & $1.2-10.8$ & \\
\hline
\end{tabular}

*Adjusted for overweight and obesity, age, and pulse oxygen saturation ( $\mathrm{SpO} 2)$.

$89.8 \mathrm{mg} / \mathrm{mL}, p=0.019)$, while serum insulin concentration was similar (9.5 vs. $7.5 \mu \mathrm{IU} / \mathrm{mL}$ ). Adjusted multivariate regression showed that the odds of developing insulin resistance in participants with EE were 2.64 times the odds observed in $\mathrm{HH}$ (Table 4). In addition, participants with EE showed a greater area under the curve in the oral glucose tolerance test revealing poor glycemic management in these subjects compared with $\mathrm{HH}(p=0.019)$. Finally, fasting serum triglycerides were higher in the EE group compared with $\mathrm{HH}(p=0.012)$, although no difference between these groups was observed for fasting total serum cholesterol, HDL or LDL.

\section{Conventional and ambulatory blood pressure}

Conventional SBP and DBP values were higher in the group with $\mathrm{EE}$ compared with $\mathrm{HH}$. ABPM measurements show that awake SBP, DBP, and mean arterial pressure (MAP) were significantly higher in the EE group. In contrast, during sleep, only DBP was significantly higher in highlanders with EE. Conventional and ABPM values of sea-level (SL) inhabitants are shown for comparison. In agreement with daytime measurements, $24 \mathrm{~h}$ SBP, DBP, and MAP were significantly higher in EE participants (Table 5). Moreover, logistic regression analysis showed that the odds of presenting awake systolic and diastolic hypertension measured by ABPM were substantially higher in the EE group compared to $\mathrm{HH}$, adjusted for overweight and obesity, age, and $\mathrm{SpO}_{2}$ (Table 4). Additional multivariate regression analysis of a relationship between $\mathrm{EE}$ and BP variability as a predictor of CVR could not detect an association between these parameters in our study sample. Finally, we show an additional comparison of the study groups with a sample of SL individuals. This comparison allows for the ob-

Table 3. Average Treatment Effect of Excessive ERYTHROCYTOSIS ON CARDIOVASCULAR RISK

\begin{tabular}{lcccc}
\hline Dependent variable & ATE & SEM & p-Value & $95 \%$ CI \\
\hline CVR & 0.065 & 0.027 & 0.017 & $0.01-0.11$ \\
\hline
\end{tabular}

ATE, average treatment effect; CVR, cardiovascular risk. servation of a gradient of BP values, in which higher values are observed in the SL sample, followed by individuals with EE, and finally the lowest values are found in $\mathrm{HH}$.

\section{Discussion}

\section{EE and CVR}

This is the first study to show an association between the presence of EE and the estimated risk of developing a cardiovascular event in the next 10 years. Our results show that, compared to healthy HA residents, participants with EE have more than three times the odds of being at high ( $>20 \%)$ risk of cardiovascular events over a 10-year follow-up, as estimated by the Framingham General Cardiovascular Risk Score.

Several observational studies at HA have shown an association between EE and metabolic and cardiovascular conditions, including some of those composing the CVR score developed from the Framingham cohort (León-Velarde and Arregui, 1994; Jefferson et al., 2002; Penaloza and AriasStella, 2007; Gonzales and Tapia, 2013; Naeije and Vanderpool, 2013; Okumiya et al., 2016). However, to date, no studies on the evaluation of a relatively short-term CVR in HA populations and on its relationship with EE have been published, probably due to the historically few cardiovascular events and low prevalence of CVR factors reported in HA residents worldwide (Hurtado, 1960; Ruiz and Peñaloza, 1977; Faeh et al., 2009; Woolcott et al., 2015). Our findings agree with those from studies at SL, which show a relationship between elevated Hct and the development of cardiovascular diseases (Mcdonough et al., 1965; Goubali et al., 1995), although the mechanisms behind this association are yet to be determined.

\section{EE and CVR factors: metabolic parameters}

At HA, elevated red blood cell count has been associated with metabolic CVR factors such as diabetes, insulin resistance (Okumiya et al., 2011, 2016), and dyslipidemia (Gonzales and Tapia, 2013). Studies in the Andes, China, and India have shown that glucose intolerance is more frequent in patients with elevated $\mathrm{Hb}$ compared with those with normal $\mathrm{Hb}$ for the altitude of residence. This is in accordance with 
Table 4. Association Between Excessive Erythrocytosis and Systolic and Diastolic Hypertension Measured by ABPM, and Between Excessive Erythrocytosis and Insulin Resistance

\begin{tabular}{|c|c|c|c|c|c|c|}
\hline \multirow[b]{2}{*}{ Variables } & \multicolumn{3}{|c|}{ Bivariate analysis } & \multicolumn{3}{|c|}{ Adjusted model* } \\
\hline & $O R$ & CI $95 \%$ & $\mathrm{p}$-value & $O R$ & CI $95 \%$ & $\mathrm{p}$ value \\
\hline \multicolumn{7}{|l|}{ Systolic hypertension } \\
\hline $\begin{array}{l}\text { Overweight and obesity } \\
\text { No }\end{array}$ & & & 0.001 & & & 0.004 \\
\hline 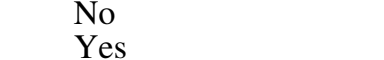 & Reference & & & Reference & & \\
\hline Age & & $2.1-19.5$ & 0.023 & & $1.1-16.4$ & 0.117 \\
\hline$<45$ & Reference & & & Reference & & \\
\hline$\geq 45$ & 2.8 & $1.1-7.0$ & & 2.1 & $0.8-56$ & \\
\hline $\mathrm{SpO}_{2}(\%)$ & & & 0.332 & & & 0.780 \\
\hline$\geq 83 \%$ & Reference & & & Reference & & \\
\hline$<83 \%$ & 1.7 & $0.6-4.9$ & & 0.8 & $0.2-2.8$ & \\
\hline CMS score & & & 0.010 & & & \\
\hline Preclinical & Reference & & & & & \\
\hline Mild & 3.5 & $1.3-9.3$ & & & & \\
\hline Moderate and severe & 4.7 & $1.3-17.2$ & & & & \\
\hline EE & & & 0.001 & & & 0.007 \\
\hline No & Reference & & & Reference & & \\
\hline Yes & 5.1 & $1.9-13.5$ & & 4.3 & $1.5-12.3$ & \\
\hline \multicolumn{7}{|l|}{ Diastolic hypertension } \\
\hline Overweight and obesity & & & 0.043 & & & 0.143 \\
\hline No & Reference & & & Reference & & \\
\hline Yes & 2.5 & $1.0-6.1$ & & 2.0 & $0.8-5.0$ & \\
\hline Age & & & 0.013 & & & 0.043 \\
\hline$<45$ & Reference & & & Reference & & \\
\hline$\geq 45$ & 3.1 & $1.3-7.5$ & & 2.6 & $1.0-6.5$ & \\
\hline $\mathrm{SpO}_{2}(\%)$ & & & 0.387 & & & 0.832 \\
\hline$\geq 83 \%$ & Reference & & & Reference & & \\
\hline$<83 \%$ & 1.6 & $0.5-4.6$ & & 0.9 & $0.3-2.8$ & \\
\hline CMS score & & & 0.002 & & & \\
\hline Preclinical & Reference & & & & & \\
\hline Mild & 5.1 & $2.0-12.8$ & & & & \\
\hline Moderate and severe & 2.0 & $0.4-10.2$ & & & & \\
\hline EE & & & 0.006 & & & 0.029 \\
\hline No & Reference & & & Reference & & \\
\hline Yes & 3.5 & $1.4-8.5$ & & 3.0 & $1.1-8.0$ & \\
\hline \multicolumn{7}{|l|}{ Insulin resistance } \\
\hline Overweight and obesity & & & 0.000 & & & 0.000 \\
\hline No & Reference & & & Reference & & \\
\hline Yes & 4.9 & $2.0-11.5$ & & 5.6 & $2.3-13.7$ & \\
\hline Age & & & 0.351 & & & 0.038 \\
\hline$<45$ & Reference & & & Reference & & \\
\hline$\geq 45$ & 0.7 & $0.3-1.4$ & & 0.4 & $0.2-0.9$ & \\
\hline $\mathrm{SpO}_{2}(\%)$ & & & 0.829 & & & 0.120 \\
\hline$\geq 83 \%$ & Reference & & & Reference & & \\
\hline$<83 \%$ & 0.9 & $0.3-2.4$ & & 0.4 & $0.1-1.3$ & \\
\hline CMS score & & & 0.076 & & & \\
\hline Preclinical & Reference & & & & & \\
\hline Mild & 2.4 & $1.1-5.2$ & & & & \\
\hline Moderate and severe & 1.0 & $0.2-4.7$ & & & & \\
\hline $\mathrm{EE}$ & & & 0.011 & & & 0.014 \\
\hline No & Reference & & & Reference & & \\
\hline Yes & 2.5 & $1.2-5.05$ & & 2.6 & $1.2-5.7$ & \\
\hline
\end{tabular}

*Adjusted for overweight and obesity, age, and pulse oxygen saturation $\left(\mathrm{SpO}_{2}\right)$.

findings of a relationship between red blood cell count, insulin resistance, and $\beta$-cell function observed at SL (Barbieri et al., 2001; Hanley et al., 2009). Conversely, studies on dyslipidemias at HA populations are scarce and inconclusive, and no association between EE and triglyceride levels has been reported so far.
Our findings of an independent association between these CVR factors and the presence of EE are in line with those reported in previous studies, and add further evidence since all risk factors have been measured in the same population. In our study, the presence of EE was associated with higher fasting serum glucose concentration and insulin resistance, and with 
Table 5. Comparison of Conventional and ambulatory Blood Pressure Measurements BetweEn SubJects With EXCESSIVE ERYTHROCYTOSIS and Healthy Highlanders fRom Cerro de Pasco, Peru (4340 M)

\begin{tabular}{|c|c|c|c|c|c|c|}
\hline & \multicolumn{2}{|c|}{$E E(\mathrm{n}=133)$} & \multicolumn{2}{|c|}{$H H(\mathrm{n}=209)$} & \multicolumn{2}{|c|}{$S L(\mathrm{n}=40)$} \\
\hline & Mean & SEM & Mean & $S E M$ & Mean & $S E M$ \\
\hline $\begin{array}{l}\text { Conventional } \\
\text { SBP }\end{array}$ & $117.3^{*}$ & 1.3 & 113.5 & 0.9 & 116.7 & 2.0 \\
\hline $\begin{array}{l}\text { Conventional } \\
\text { DBP }\end{array}$ & $77.4^{*}$ & 0.9 & 75.4 & 0.7 & 77.2 & 1.6 \\
\hline $24 \mathrm{~h} \mathrm{SBP}$ & $118.1^{*}$ & 1.2 & $113.7^{\# \# \#}$ & 0.7 & 123.2 & 1.4 \\
\hline $24 \mathrm{~h}$ DBP & $74.8 * *$ & 0.8 & 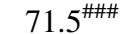 & 0.5 & 74.5 & 0.9 \\
\hline $24 \mathrm{~h}$ MAP & $88.6^{* *}$ & 0.9 & $85.4^{\# \# \#}$ & 0.5 & 90.4 & 0.9 \\
\hline Awake SBP & $123.9 * * *$ & 1.2 & $118.8^{\#}$ & 0.8 & $127.5^{\dagger \dagger \dagger}$ & 1.5 \\
\hline Awake DBP & $78.9 * * *$ & 0.8 & $75.4^{\#}$ & 0.5 & 77.5 & 0.9 \\
\hline Awake MAP & $93.6 * * *$ & 0.9 & $89.5^{\# \# \#}$ & 0.6 & 93.9 & 1.0 \\
\hline Sleep SBP & 102.1 & 1.3 & $100.5^{\# \# \#}$ & 0.9 & $108.4^{\dagger \dagger \dagger}$ & 1.4 \\
\hline Sleep DBP & $63.8 *$ & 0.8 & $61.6^{\#}$ & 0.6 & 64.8 & 1.1 \\
\hline Sleep MAP & 76.3 & 0.9 & $74.2^{\# \# \#}$ & 0.7 & $78.6^{\dagger}$ & 1.0 \\
\hline
\end{tabular}

Sea-level (SL) values from Lima, Peru $(150 \mathrm{~m})$ are shown for comparison.

$* p<0.05$ versus $\mathrm{HH}$.

$* * p<0.01$ versus $\mathrm{HH}$

$* * * p<0.001$ versus $\mathrm{HH}$.

${ }^{\#} p<0.05$ versus SL.

$\# \# \#<0.001$ versus SL.

${ }^{\dagger} p<0.05$ versus EE.

$\dagger \dagger p<0.001$ versus EE.

DBP, diastolic blood pressure; MAP, mean arterial pressure; SBP systolic blood pressure.

higher fasting serum triglycerides concentration. In addition, a greater area under the curve in the oral glucose tolerance test in EE participants suggests poor glycemic management in these subjects.

\section{EE and CVR factors: Blood pressure}

While several studies have been published on the effects of EE on pulmonary circulation and the occurrence of cardiovascular events such as right heart failure and pulmonary hypertension (Penaloza and Arias-Stella, 2007; Naeije and Vanderpool, 2013), investigations regarding the systemic circulation in the population with EE are scarce (LeónVelarde and Arregui, 1994; Richalet et al., 2005; Maignan et al., 2009). For example, only few studies have reported conventional blood pressure values in highlanders with EE (Richalet et al., 2005; Maignan et al., 2009). In the present study, we report blood pressure parameters measured conventionally and with $24 \mathrm{~h}$ ABPM. ABPM is a technique, which allows a more accurate assessment of the actual daily life blood pressure status of an individual than conventional measurements in the doctor's office, and was shown to be particularly useful in assessing blood pressure changes during acute HA exposure (Parati et al., 2014a; Bilo et al., 2015).

Our results of ABPM measurements show a strong association between daytime systolic and diastolic hypertension and the presence of EE. In addition, night-time DBP was found associated with the presence of EE in our study sample. The latter association carries a high predictive value, since at night-time there is no interference from other factors that might affect BP variability such as physical activity, emotional stress and environmental stimulations (O'Brien et al., 2013; Parati et al., 2014b).
Our findings of an association between systemic hypertension and EE using $24 \mathrm{~h}$ ABPM agree with the results of previous studies where only conventional BP measurements were used (León-Velarde and Arregui, 1994; Jefferson et al., 2002). Interestingly, at SL, a study by Bertinieri and some of the authors of this article showed in hypertensive patients with primary polycythemia that the reduction of Hct by isovolemic hemodilution resulted in a significant fall in both conventional and $24 \mathrm{~h}$ ambulatory blood pressure, supporting the hypothesis of a direct relationship between elevated Hct and hypertension (Bertinieri et al., 1998).

In addition, our results of comparisons with SL values show that $\mathrm{HH}$ have lower BP than SL residents, for both daytime and night-time ABPM measurements. These results are in agreement with what has been historically found in observational studies of comparisons in conventional BP values and prevalence of HTA between SL and HA populations (Hurtado, 1960; Marticorena et al., 1969; Negi et al., 2012). The consistency of these observations through different studies suggests that a protection from HTA is present in healthy HA populations, when compared to SL. Interestingly, BP values from the EE group observed in the present study were not significantly different from those found at SL for most ABPM parameters. This supports the hypothesis of a loss of cardiovascular protection in subjects with EE compared with $\mathrm{HH}$.

\section{EE and CVR factors: Iron profile}

Observational studies have suggested that iron profile alterations such as elevated serum iron concentration and ferritin levels might increase the risk of cardiovascular outcomes (Kraml, 2017; Silvestre et al., 2017). Cardiovascular atherosclerosis has been associated with increased iron concentration (Kiechl et al., 1997), and a modest direct relationship has been reported between ferritin levels and metabolic syndrome (Abril-Ulloa et al., 2014). In contrast, a recent meta-analysis of prospective studies shows no association between elevated baseline serum ferritin concentrations and the occurrence of coronary heart disease or myocardial infarction (Das De et al., 2015). These contradictory results indicate that there is still inconsistency in the evidence for the association between iron profile and cardiovascular outcomes. Our results indicate that the higher CVR associated to $\mathrm{EE}$ was not related to changes in iron profile, since we found similar iron concentrations in $\mathrm{HH}$ and EE subjects, and even lower ferritin values in the EE group; a finding which is in the opposite direction in relationship to the proposed association. Moreover, iron profile mean values were within the reference range, which suggests that lower ferritin levels might be an indicator of a new steady-state of decreased iron stores due to increased erythropoiesis.

\section{Potential mechanisms of the relationship between EE and CVR}

Although the mechanisms behind the association between $\mathrm{EE}$ and a number of cardiovascular parameters and between the former and CVR are still unclear, some possible explanations for these findings have been suggested. These include an impact of elevated blood viscosity secondary to the EE on several variables involved in cardiovascular function, CVR factors, and CVR, given the major role of red blood cell count as a determinant of blood viscosity (Chien, 1975; Pasquini 


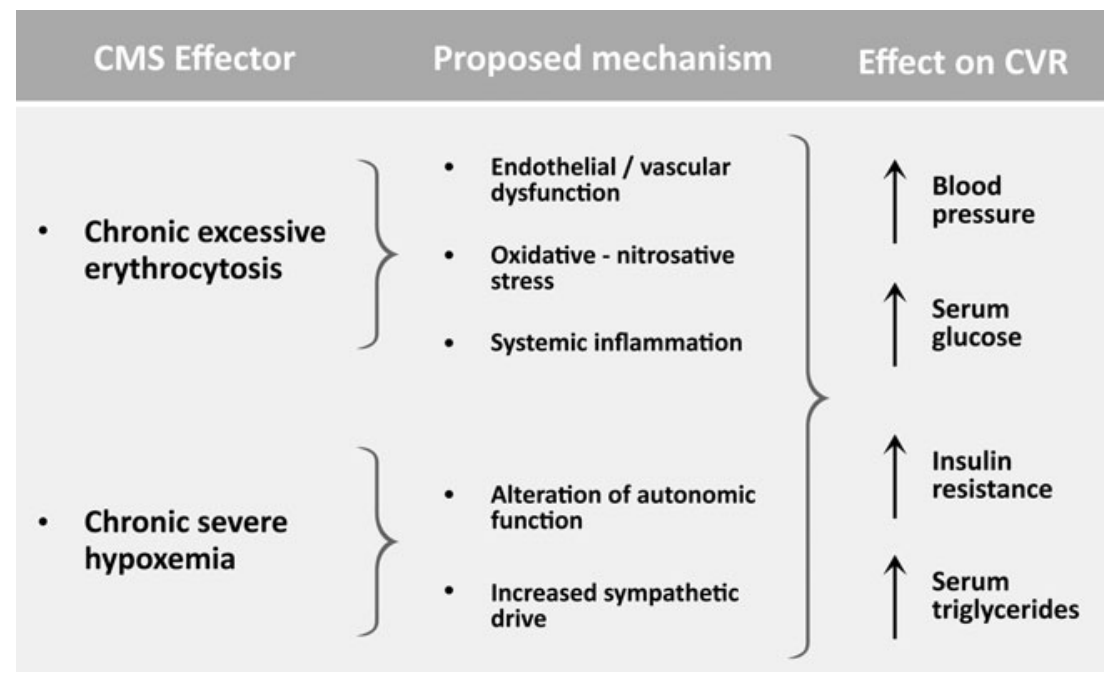

FIG. 1. Proposed mechanisms for the association between excessive erythrocytosis and CVR. EE and chronic severe hypoxemia, characteristics of CMS, could contribute to increased CVR through their effects on endothelial and vascular function, oxidative/nitrosative stress, inflammation, and alteration of autonomic function. These effects are reflected in increased BP, altered glucose management, and increased serum lipid levels. CMS, chronic mountain sickness; CVR, cardiovascular risk; EE, excessive erythrocytosis.

et al., 1983) as well as an effect of severe hypoxemia on these parameters and on sympathetic activity (Fig. 1).

Rimoldi et al. (2012) evaluated the direct effect of blood viscosity on vascular function at HA by performing hemodilutions in CMS highlanders in the absence of other CVR factors. Before hemodilution, CMS subjects presented vascular dysfunction evidenced by impaired flow-mediated dilation (FMD), arterial stiffness, and greater carotid intimamedia thickness compared to $\mathrm{HH}$, suggesting an association between CMS and vascular endothelial dysfunction. Conversely, hemodilution had no detectable effect on vascular function evaluated by FMD. According to the authors, this finding suggests that blood viscosity secondary to EE does not contribute importantly to the observed vascular dysfunction in CMS highlanders. However, their study offers information only on the acute effect of $\mathrm{EE}$ on vascular structure and function and not on its chronic effects, which might not be reversible in a short-term follow-up. In a subsequent study, the same research group reported exaggerated oxidative-nitrosative stress in CMS highlanders, which was associated with vascular dysfunction (Bailey et al., 2013). These results support the hypothesis of a detrimental effect of $\mathrm{EE}$ on vascular function that might have an impact on CVR. However, further studies are needed to evaluate the chronic effects of EE and the associated elevated blood viscosity on cardiovascular function and on inflammation and damage to other important tissues.

The detrimental effect of the interplay between hemorheological factors, oxidative stress, and inflammation observed on several tissues in animal models suggest that these mechanisms are potential candidates to explain the negative consequences of $\mathrm{EE}$ on $\beta$-cell function, insulin resistance, and glycemic control in humans. Studies at SL have shown that hyperviscosity and elevated Hct have a negative impact on pancreatic $\beta$-cell function and insulin sensitivity, and on glucose disposal rate, affecting blood glucose concentrations (Moan et al., 1994; Irace et al., 2014). Furthermore, high blood viscosity can generate inflammation, fibrosis, and an increment in oxidative stress, causing damage to tissues involved in glucose metabolism (Hanley et al., 2009). Accordingly, a correlation between $\mathrm{Hb}$ concentration and insulin resistance has been observed at SL (Barbieri et al., 2001; Hanley et al., 2009), suggesting a role for high blood viscosity on glycemic control.

An additional mechanism contributing to the relationship between EE and CVR is the severely reduced $\mathrm{SpO}_{2}$ observed in subjects with EE. This contribution might be through an effect of hypoxemia on CVR factors, independently of EE, or through its impact on sympathetic activity.

Miele et al. (2016) reported a modest independent association between a reduction in $\mathrm{SpO}_{2}$, even within normal altitude values range, and the odds of having metabolic syndrome and elevated glycosylated hemoglobin in a crosssectional sample of adults from Puno, Peru at $3825 \mathrm{~m}$. The results of this study imply that any degree of chronic hypoxemia may worsen metabolic status, which is controversial given findings of cardiometabolic protection conferred by chronic hypoxia to HA dwellers (Baracco et al., 2007; Faeh et al., 2009; Woolcott et al., 2015) in contrast with evidence of the negative effects of severe hypoxemia on cardiometabolic outcomes (Schroeder et al., 2003; Drager et al., 2013; Herrscher et al., 2014).

Rimoldi et al. evaluated the effect of oxygenation on vascular control and showed that oxygen inhalation significantly improved vascular function in hypoxemic highlanders, but it did not normalize these parameters when compared with their values observed in normoxemic $\mathrm{HH}$, suggesting that other mechanisms in addition to hypoxemia might be involved in the observed vascular damage and in explaining its effects on the cardiovascular system ( $\mathrm{Ri}-$ moldi et al., 2012). In our study, we found that the association between EE and CVR, and the association between $\mathrm{EE}$ and CVR factors persisted after adjusting for $\mathrm{SpO}_{2}$, supporting the hypothesis of additional mechanisms besides hypoxemia contributing to the relationship between these conditions. 
Severe hypoxemia in highlanders with EE might also be related to cardiovascular changes through an alteration of autonomic function. A study by Moore et al. suggested an effect of hypoxia on carotid baroreceptor function, with a higher "set-point" for vasoconstrictor stimuli (Moore et al., 2006) in CMS subjects. In addition, Antezana et al. (1995) showed changes in sympathetic activity and increased plasma catecholamines in CMS. Together, these findings suggest a role for altered sympathetic drive associated to differences in CVR between highlanders with EE and healthy HA natives.

Moreover, increased sympathetic activity has been associated with insulin resistance in healthy subjects at SL (Lembo et al., 1994; Reaven et al., 1996). It is possible that this association also contributes to the alterations in glucose metabolism observed in CMS highlanders, and therefore to their cardiometabolic status. However, further studies are needed to define the possible role of autonomic nervous system dysfunction in explaining the relationship between EE and CVR.

\section{Strengths and limitations}

A limitation of the present study is the lack of populationspecific threshold values for the diagnosis of risk factors and of CVR in HA dwellers. Those currently available were obtained from analyses of SL populations and developed from international cohorts (WHO, 2007; D'Agostino et al., 2008; Duerden et al., 2015) and thus might not be fully applicable to HA populations, for which further validation is still needed. Nevertheless, since the comparison between groups used the same thresholds, the differences observed maintain validity and are not likely to be affected by the cutoff values. In addition, the CVR score used in this study has been validated for Latin American populations (D’Agostino et al., 2001). However, further prospective studies to validate CVR scores in specific Andean locations at different altitudes are required.

It is also important to mention that the CVR calculated for the present study is a predictor of risk over a relatively shortterm follow-up, while it does not estimate the risk of cardiovascular event at any further time point in life. This is important because a recent study in Peru has reported that more than half of the study subjects classified as having low CVR in the short term were at high risk of suffering a cardiovascular event at some point in their lives (Quispe et al., 2015). These findings highlight the relevance of a correct estimation of CVR on different populations, given its impact on the development of public health policies for primary and secondary prevention. This is particularly important in populations with aggravating risk factors, which might be the case of highlanders with EE.

An additional limitation is the inclusion of male participants only. This was due to their higher prevalence of EE compared with women (León-Velarde and Arregui, 1994; Wu et al., 1998), and because of the absence of confounding factors such as menopause, which is well known to have important effects both on erythrocytosis and CVR. In addition, studying male participants allowed for comparison with previous studies in highlanders with EE and CMS. Despite this limitation, the present study offers relevant information to challenge the current knowledge in this field, although its findings need to be confirmed by further epidemiological studies in the Andean HA population.

Finally, the study used a convenience sampling for the recruitment of participants mainly due to its practicality and inexpensiveness, and because in the context of our study aim (association between $\mathrm{EE}$ and $\mathrm{CVR}$ ), the representativeness of the target population is not a requirement as long as the association of interest is maintained. In addition, given that both study groups have been selected through the same method, no differential selection between study groups was expected. Regarding internal validity, convenience sampling could lead to unbalances between the exposed and unexposed groups in terms of potential confounders that could generate biased results. To control for potential confounding in our study, we have used multiple regression and a sensitivity analysis using propensity score matching to test for the robustness of the association.

\section{Conclusions}

In conclusion, our results show that the odds of developing cardiovascular events in the next 10 years is higher in subjects with EE compared with $\mathrm{HH}$, and that the odds is even higher in the subgroup of highlanders with moderate to severe CMS, compared with mild CMS.

In addition, we found an association between CVR factors, independently considered, and the presence of EE. In separate regression models, we show higher odds of increased CVR associated with an elevation of daytime systolic and diastolic hypertension, of fasting glycemia and insulin resistance, and of fasting serum triglyceride concentration in highlanders with EE compared with $\mathrm{HH}$.

The observed associations might be explained by the detrimental effects of elevated blood viscosity and EE on several variables involved in cardiovascular and metabolic function, which might indirectly increase CVR, in addition to its direct impact on the development of cardiovascular events. However, further studies are needed to evaluate the mechanisms of the chronic effects of EE and the associated elevated blood viscosity on CVR, and of the direct or indirect effects of severe hypoxemia on cardiovascular function.

Overall, our results indicate that highlanders with EE are at higher risk of suffering from cardiovascular disease, suggesting that the HA-induced protection against cardiovascular and metabolic diseases is not present in Andeans with EE. Therefore, our findings highlight the necessity of regular control of glycemia and insulinemia (or insulin sensitivity tests), blood lipids, and blood pressure evaluation by ABPM, in addition to the usual regular (6-12 months) Hct and CMS score check-ups, to provide adequate healthcare to highlanders with EE.

\section{Acknowledgments}

We thank Mr. Gianfranco Aicardi for technical assistance, Mr. Andy Mercado for his valuable help during fieldwork, and the volunteers who took part in the study. We are also grateful to A\&D Medical (Tokyo, Japan) for supplying part of the blood pressure monitors used in the study.

This research was supported by a Wellcome Trust Public Health and Tropical Medicine Fellowship (107544/Z/15/Z) to F.C. Villafuerte.

\section{Author Disclosure Statement}

The authors declare no conflicts of interest with industry in relationship to this article. 


\section{References}

Abril-Ulloa V, Flores-Mateo G, Solà-Alberich R, Manuel-yKeenoy B, and Arija V. (2014). Ferritin levels and risk of metabolic syndrome: Meta-analysis of observational studies. BMC Public Health 14:483.

Antezana AM, Richalet JP, Noriega I, Galarza M, and Antezana G. (1995). Hormonal changes in normal and polycythemic high-altitude natives. J Appl Physiol (1985) 79:795-800.

Aparicio NJ, Puchulu FE, Gagliardino JJ, Ruiz M, Llorens JM, Ruiz J, Lamas A, and De Miguel R. (1974). Circadian variation of the blood glucose, plasma insulin and human growth hormone levels in response to an oral glucose load in normal subjects. Diabetes 23:132-137.

Bailey DM, Rimoldi SF, Rexhaj E, Pratali L, Salinas Salmòn C, Villena M, McEneny J, Young IS, Nicod P, Allemann Y, Scherrer U, and Sartori C. (2013). Oxidative-nitrosative stress and systemic vascular function in highlanders with and without exaggerated hypoxemia. Chest 143:444-451.

Baracco R, Mohanna S, and Seclen S. (2006). Determination of insulin sensitivity using the HOMA method in high altitude and sea-level adult populations [in Spanish]. Rev Med Hered 17: 206-211.

Baracco R, Mohanna S, and Seclén S. (2007). A comparison of the prevalence of metabolic syndrome and its components in high and low altitude populations in Peru. Metab Syndr Relat Disord 5:55-62.

Barbieri M, Ragno E, Benvenuti E, Zito GA, Corsi A, Ferrucci L, and Paolisso G. (2001). New aspects of the insulin resistance syndrome: Impact on haematological parameters. Diabetologia 44:1232-1237.

Bellido D, Barragán M, and Colque N. (1993). Lipid profile in the Viacha population [in Spanish]. Acta Andina 2:28-29.

Bertinieri G, Parati G, Ulian L, Santucciu C, Massaro P, Cosentini R, Torgano G, Morganti A, and Mancia G. (1998). Hemodilution reduces clinic and ambulatory blood pressure in polycythemic patients. Hypertens Dallas Tex 1979 31:848853.

Bilo G, Villafuerte FC, Faini A, Anza-Ramírez C, Revera M, Giuliano A, Caravita S, Gregorini F, Lombardi C, Salvioni E, Macarlupu JL, Ossoli D, Landaveri L, Lang M, Agostoni P, Sosa JM, Mancia G, and Parati G. (2015). Ambulatory blood pressure in untreated and treated hypertensive patients at high altitude: The High Altitude Cardiovascular Research-Andes study. Hypertens Dallas Tex (1979) 65:1266-1272.

Chien S. 1975. Biophysical behavior of red cells in suspensions. In: The Red Blood Cell. D.M. Surgenor, ed. Academic Press, New York. pp. 1031-1133.

Craig CL, Marshall AL, Sjöström M, Bauman AE, Booth ML, Ainsworth BE, Pratt M, Ekelund U, Yngve A, Sallis JF, and Oja P. (2003). International physical activity questionnaire: 12-country reliability and validity. Med Sci Sports Exerc 35: 1381-1395.

D’Agostino RB, Grundy S, Sullivan LM, Wilson P, and CHD Risk Prediction Group. (2001). Validation of the Framingham coronary heart disease prediction scores: Results of a multiple ethnic groups investigation. JAMA 286:180-187.

D'Agostino RB, Vasan RS, Pencina MJ, Wolf PA, Cobain M, Massaro JM, and Kannel WB. (2008). General cardiovascular risk profile for use in primary care: The Framingham Heart Study. Circulation 117:743-753.

Danesh J, Collins R, Peto R, and Lowe GD. (2000). Haematocrit, viscosity, erythrocyte sedimentation rate: Metaanalyses of prospective studies of coronary heart disease. Eur Heart J 21:515-520.
Das De S, Krishna S, and Jethwa A. (2015). Iron status and its association with coronary heart disease: Systematic review and meta-analysis of prospective studies. Atherosclerosis 238:296-303.

De Ferrari A, Miranda JJ, Gilman RH, Dávila-Román VG, León-Velarde F, Rivera-Ch M, Huicho L, Bernabé-Ortiz A, Wise RA, Checkley W, and CRONICAS Cohort Study Group. (2014). Prevalence, clinical profile, iron status, and subject-specific traits for excessive erythrocytosis in andean adults living permanently at 3825 meters above sea level. Chest 146:1327-1336.

Drager LF, Togeiro SM, Polotsky VY, and Lorenzi-Filho G. (2013). Obstructive sleep apnea: A cardiometabolic risk in obesity and the metabolic syndrome. J Am Coll Cardiol 62: 569-576.

Duerden M, O'Flynn N, and Qureshi N. (2015). Cardiovascular risk assessment and lipid modification: NICE guideline. Br J Gen Pract J R Coll Gen Pract 65:378-380.

Faeh D, Gutzwiller F, Bopp M, and Swiss National Cohort Study Group. (2009). Lower mortality from coronary heart disease and stroke at higher altitudes in Switzerland. Circulation 120:495-501.

Gakidou E, Mallinger L, Abbott-Klafter J, Guerrero R, Villalpando S, Ridaura RL, Aekplakorn W, Naghavi M, Lim S, Lozano R, and Murray CJL. (2011). Management of diabetes and associated cardiovascular risk factors in seven countries: A comparison of data from national health examination surveys. Bull World Health Organ 89:172-183.

Gonzales GF, and Tapia V. (2013). Association of high altitudeinduced hypoxemia to lipid profile and glycemia in men and women living at $4100 \mathrm{~m}$ in the Peruvian Central Andes. Endocrinol Nutr Órgano Soc Esp Endocrinol Nutr 60:79-86.

Goubali A, Voukiklaris G, Kritsikis S, Viliotou F, and Stamatis D. (1995). Relation of hematocrit values to coronary heart disease, arterial hypertension, and respiratory impairment in occupational and population groups of the Athens area. Angiology 46:719-725.

Hanley AJG, Retnakaran R, Qi Y, Gerstein HC, Perkins B, Raboud J, Harris SB, and Zinman B. (2009). Association of hematological parameters with insulin resistance and betacell dysfunction in nondiabetic subjects. J Clin Endocrinol Metab 94:3824-3832.

Herrscher TE, Overland B, Sandvik L, Westheim AS, and Akre H. (2014). High cardiovascular risk profile in patients with sleep apnea. Laryngoscope 124:306-310.

Hurtado A. (1960). Some clinical aspects of life at high altitudes. Ann Intern Med 53:247-258.

Instituto Nacional de Estadística e Informática. (2007). National Census of Population and Housing. Peru [in Spanish]. 2007. Available at http://censos.inei.gob.pe/censos2007/documentos/ Resultado_CPV2007.pdf (accessed October 10, 2017).

Irace C, Carallo C, Scavelli F, De Franceschi MS, Esposito T, and Gnasso A. (2014). Blood viscosity in subjects with normoglycemia and prediabetes. Diabetes Care 37:488-492.

Jefferson JA, Escudero E, Hurtado M-E, Kelly JP, Swenson ER, Wener MH, Burnier M, Maillard M, Schreiner GF, Schoene RB, Hurtado A, and Johnson RJ. (2002). Hyperuricemia, hypertension, and proteinuria associated with high-altitude polycythemia. Am J Kidney Dis 39:1135-1142.

Kiechl S, Willeit J, Egger G, Poewe W, and Oberhollenzer F. (1997). Body iron stores and the risk of carotid atherosclerosis: Prospective results from the Bruneck study. Circulation 96:3300-3307.

Kraml P. (2017). The role of iron in the pathogenesis of atherosclerosis. Physiol Res 66:S55-S67. 
Le Floch JP, Escuyer P, Baudin E, Baudon D, and Perlemuter L. (1990). Blood glucose area under the curve. Methodological aspects. Diabetes Care 13:172-175.

Lembo G, Capaldo B, Rendina V, Iaccarino G, Napoli R, Guida R, Trimarco B, and Saccá L. (1994). Acute noradrenergic activation induces insulin resistance in human skeletal muscle. Am J Physiol 266:E242-E247.

León-Velarde F, and Arregui A. (1994). Maladaptation to life at high-altitude [in Spanish]. Institut francais d'études andines (IFEA), Lima.

León-Velarde F, Maggiorini M, Reeves JT, Aldashev A, Asmus I, Bernardi L, Ge R-L, Hackett P, Kobayashi T, Moore LG, Penaloza D, Richalet J-P, Roach R, Wu T, Vargas E, ZubietaCastillo G, and Zubieta-Calleja G. (2005). Consensus statement on chronic and subacute high altitude diseases. High Alt Med Biol 6:147-157.

Maignan M, Rivera-Ch M, Privat C, Leòn-Velarde F, Richalet J-P, and Pham I. (2009). Pulmonary pressure and cardiac function in chronic mountain sickness patients. Chest 135: 499-504.

Mancia G, Di Rienzo M, and Parati G. (1993). Ambulatory blood pressure monitoring use in hypertension research and clinical practice. Hypertens Dallas Tex 1979 21:510-524.

Marticorena E, Ruiz L, Severino J, Galvez J, and Peñaloza D. (1969). Systemic blood pressure in white men born at sea level: Changes after long residence at high altitudes. Am J Cardiol 23:364-368.

Mcdonough JR, Hames CG, Garrison GE, Stulb SC, Lichtman MA, and Hefelfinger DC. (1965). The relationship of hematocrit to cardiovascular states of health in the negro and white population of Evans County, Georgia. J Chronic Dis 18:243-257.

Miele $\mathrm{CH}$, Schwartz AR, Gilman RH, Pham L, Wise RA, Davila-Roman VG, Jun JC, Polotsky VY, Miranda JJ, LeonVelarde F, and Checkley W. (2016). Increased cardiometabolic risk and worsening hypoxemia at high altitude. High Alt Med Biol 17:93-100.

Moan A, Nordby G, Os I, Birkeland KI, and Kjeldsen SE. (1994). Relationship between hemorrheologic factors and insulin sensitivity in healthy young men. Metabolism 43:423 427.

Monge-C C, Arregui A, and León-Velarde F. (1992). Pathophysiology and epidemiology of chronic mountain sickness. Int J Sports Med 13 Suppl 1:S79-S81.

Moore JP, Claydon VE, Norcliffe LJ, Rivera-Ch MC, LèonVelarde F, Appenzeller O, and Hainsworth R. (2006). Carotid baroreflex regulation of vascular resistance in high-altitude Andean natives with and without chronic mountain sickness. Exp Physiol 91:907-913.

Mortimer EA, Monson RR, and MacMahon B. (1977). Reduction in mortality from coronary heart disease in men residing at high altitude. N Engl J Med 296:581-585.

Naeije R, and Vanderpool R. (2013). Pulmonary hypertension and chronic mountain sickness. High Alt Med Biol 14:117125.

Negi PC, Bhardwaj R, Kandoria A, Asotra S, Ganju N, Marwaha R, Sharma R, and Kanwar A. (2012). Epidemiological study of hypertension in natives of Spiti Valley in Himalayas and impact of hypobaric hypoxemia; a cross-sectional study. J Assoc Physicians India 60:21-25.

O’Brien E, Parati G, Stergiou G, Asmar R, Beilin L, Bilo G, Clement D, de la Sierra A, de Leeuw P, Dolan E, Fagard R, Graves J, Head GA, Imai Y, Kario K, Lurbe E, Mallion J-M, Mancia G, Mengden T, Myers M, Ogedegbe G, Ohkubo T, Omboni S, Palatini P, Redon J, Ruilope LM, Shennan A, Staessen JA, vanMontfrans G,
Verdecchia P, Waeber B, Wang J, Zanchetti A, Zhang Y, and European Society of Hypertension Working Group on Blood Pressure Monitoring. (2013). European Society of Hypertension position paper on ambulatory blood pressure monitoring. J Hypertens 31:1731-1768.

Okumiya K, Sakamoto R, Kimura Y, Ishimoto Y, Wada T, Ishine M, Ishikawa M, Nakajima S, Hozo R, Ge R-L, Norboo T, Otsuka K, and Matsubayashi K. (2010). Strong association between polycythemia and glucose intolerance in elderly high-altitude dwellers in Asia. J Am Geriatr Soc 58:609-611. Okumiya K, Sakamoto R, Fukutomi E, Kimura Y, Ishimoto Y, Chen W, Ishikawa M, Hozo R, Otsuka K, Matsubayashi K, Wada T, Inamura T, Lazo M, Lu JP, and Garcia PJ. (2011). Strong association between polycythemia and glucose intolerance in older adults living at high altitudes in the Andes. J Am Geriatr Soc 59:1971-1973.

Okumiya K, Sakamoto R, Ishimoto Y, Kimura Y, Fukutomi E, Ishikawa M, Suwa K, Imai H, Chen W, Kato E, Nakatsuka M, Kasahara Y, Fujisawa M, Wada T, Wang H, Dai Q, Xu H, Qiao H, Ge R-L, Norboo T, Tsering N, Kosaka Y, Nose M, Yamaguchi T, Tsukihara T, Ando K, Inamura T, Takeda S, Ishine M, Otsuka K, and Matsubayashi K. (2016). Glucose intolerance associated with hypoxia in people living at high altitudes in the Tibetan highland. BMJ Open 6:e009728.

Parati G, Bilo G, Faini A, Bilo B, Revera M, Giuliano A, Lombardi C, Caldara G, Gregorini F, Styczkiewicz K, Zambon A, Piperno A, Modesti PA, Agostoni P, and Mancia G. (2014a). Changes in $24 \mathrm{~h}$ ambulatory blood pressure and effects of angiotensin II receptor blockade during acute and prolonged high-altitude exposure: A randomized clinical trial. Eur Heart J 35:3113-3122.

Parati G, Stergiou G, O’Brien E, Asmar R, Beilin L, Bilo G, Clement D, de la Sierra A, de Leeuw P, Dolan E, Fagard R, Graves J, Head GA, Imai Y, Kario K, Lurbe E, Mallion J-M, Mancia G, Mengden T, Myers M, Ogedegbe G, Ohkubo T, Omboni S, Palatini P, Redon J, Ruilope LM, Shennan A, Staessen JA, vanMontfrans G, Verdecchia P, Waeber B, Wang J, Zanchetti A, Zhang Y, and European Society of Hypertension Working Group on Blood Pressure Monitoring and Cardiovascular Variability. (2014b). European Society of Hypertension practice guidelines for ambulatory blood pressure monitoring. J Hypertens 32:1359-1366.

Pasquini G, Albanese B, Manescalchi PG, and Morini R. (1983). Relation of blood viscosity, plasma viscosity and hematocrit [in Italian]. Ric Clin Lab 13 Suppl 3:327-331.

Penaloza D, and Arias-Stella J. (2007). The heart and pulmonary circulation at high altitudes: Healthy highlanders and chronic mountain sickness. Circulation 115:1132-1146.

Picon Reategui E. (1963). Intravenous glucose tolerance test at sea level and at high altitudes. J Clin Endocrinol Metab 23: 1256-1261.

Quispe R, Bazo-Alvarez JC, Burroughs Peña MS, Poterico JA, Gilman RH, Checkley W, Bernabé-Ortiz A, Huffman MD, Miranda JJ, PERU MIGRANT Study, and CRONICAS Cohort Study Group. (2015). Distribution of short-term and lifetime predicted risks of cardiovascular diseases in peruvian adults. J Am Heart Assoc 4:e002112.

Reaven GM, Lithell H, and Landsberg L. (1996). Hypertension and associated metabolic abnormalities - the role of insulin resistance and the sympathoadrenal system. N Engl J Med 334:374-381.

Richalet J-P, Rivera M, Bouchet P, Chirinos E, Onnen I, Petitjean O, Bienvenu A, Lasne F, Moutereau S, and León-Velarde F. (2005). Acetazolamide: A treatment for chronic mountain sickness. Am J Respir Crit Care Med 172:1427-1433. 
Rimoldi SF, Rexhaj E, Pratali L, Bailey DM, Hutter D, Faita F, Salmòn CS, Villena M, Nicod P, Allemann Y, Scherrer U, and Sartori C. (2012). Systemic vascular dysfunction in patients with chronic mountain sickness. Chest 141:139146.

Ruiz L, and Peñaloza D. (1977). Altitude and hypertension. Mayo Clin Proc 52:442-445.

Schroeder EB, Welch VL, Couper D, Nieto FJ, Liao D, Rosamond WD, and Heiss G. (2003). Lung function and incident coronary heart disease: The Atherosclerosis Risk in Communities Study. Am J Epidemiol 158:1171-1181.

Silvestre OM, Gonçalves A, Nadruz W, Claggett B, Couper D, Eckfeldt JH, Pankow JS, Anker SD, and Solomon SD. (2017). Ferritin levels and risk of heart failure-the Atherosclerosis Risk in Communities Study. Eur J Heart Fail 19:340-347.

Woolcott OO, Ader M, and Bergman RN. (2015). Glucose homeostasis during short-term and prolonged exposure to high altitudes. Endocr Rev 36:149-173.

World Health Organization. (2007). Prevention of Cardiovascular Disease. Guidelines for Assessment and Management of Cardiovascular Risk. Available at: www.who.int/cardiovascular_ diseases/publications/en/ (accessed January 5, 2017).

World Health Organization. (2014). Noncommunicable diseases country profiles. 2014. Available at: www.who.int/ $\mathrm{nmh} /$ publications/ncd-profiles-2014/en/(accessed January 5, 2017).
World Health Organization. (2016). WHO Methods and Data Sources for Country-Level Causes of Death 2000-2015. Available at: http://www.who.int/healthinfo/global_burden_ disease/en/ (accessed January 21, 2017).

Wu TY, Li W, Ge R-L, Cheng Q, Wang Z, Zhao G, Wei L, Jin Y, and Don G. (1998). Epidemiology of chronic mountain sickness: Ten years study in Qinghai-Tibet. In: Progress in Mountain Medicine and High Altitude Physiology. H Ohno, T Kobayashi, S Masuyama, and M Nakashima, eds. Press Committee of the 3rd World Congress on Mountain Medicine and High Altitude Physiology, Matsumoto, Japan. pp. 120-125.

Address correspondence to: Francisco C. Villafuerte, DPhil Laboratorio de Fisiología Comparada Departamento de Ciencias Biológicas y Fisiológicas Facultad de Ciencias y Filosofía Universidad Peruana Cayetano Heredia Avenue Honorio Delgado 430 Lima 31 Peru

E-mail: francisco.villafuerte@upch.pe

Received September 21, 2017; accepted in final form March 9, 2018. 